$$
\begin{aligned}
& \text { NGW-3465 } \\
& 1 N-46-42 \\
& 40+56
\end{aligned}
$$

\title{
Electromagnetic Components of Auroral Hiss and Lower Hybrid Waves in the Polar Magnetosphere
}

\author{
H. K. Wong \\ Department of Space Science. Southwest Research Institute. San Antonio. Texas
}

\begin{abstract}
DE-1 has trequently observed waves tn the whistler and lower nybrid frequencies range. Besides the electrostatic components. these waves aiso exhibit electromagnetic components. It is generaily betieved that these waves are excited by the electron acoustic instability and the electron-beamdriven lower hybrid instability. Because the electron acoustic and the lower hybrid waves are predominately electrostatic waves. they can not account for the observed electromagnetic components. In this work. it is suggested that these electromagnetic components can be explained by waves that are generated near the resonance cone and that propagate away from the source. The role that these electromagnetic waves can play in particle acceleration processes at low altitude is discussed.
\end{abstract}

\section{INTRODUCTION}

The Linh's polar magnetosphere has long been recognized as an active region of wave activities. In the last (wo decades. numerous spacecraft have sampied this region if space and have identified a large vanety of wave modes. most nitably. the auroral hiss and the auroral kilometnc radiacion ifor a review, see Shawhan. 1979). These waves are belicved to play an important role in various plasma processis in the magnetosphere through wave-particle interacuons. Examples of such processes include the diffusion of auroral electrons by electrostatic clectron cyciotron waves (Ashour-Abdalla and Kennel, 1978); the generation of the auroral kilometric radiation through relativisuc cyclotron resonance (Gurnett. 1974: Wu and Lee. 1979); ind the acceleration and heating of ions and electrons by waves in the auroral region, leading to the formation of iun and electron conical distributions (Chang et al., 1986; l.ysak. 1196: Wong et al.. 1988; Crew et al.. 1990; Temerin and (ravins. 1990).

( )ne of the wave modes that has been extensively studied in the rist is the whistler mode. This is mainly due to the

Space Piasmas: Coupling Between Small

und Medium Scale Processes

(jeupn:wial Monograph 86

Cunvroni 1905 by the American Geophysical Union interest in VLF emissions, auroral hiss, and lighting-related phenomena. In the mid-altitude polar magnetosphere. the electron plasma trequency $\omega_{\text {pe }}$ is typically less than the electron cyctotron trequency $\Omega$. Under this condition. the whistler mode propagates between the lower hybrid trequency, which is approximately the ion plasma irequency $\omega_{p}$, and the electron plasma trequency. The frequentiy observed whistler mode auroral hiss is believed to be generated near the resonance cone by either precipitating clectrons or upward moving electron beams (Gurnett et al., 1983). Another wave mode that has received considerable attention is the lower hybrid wave. The lower hybrid wave has also been observed in the auroral zone and the polar cusp and can be generated near the resonance cone by either in electron beam or an ion ring distribution (Maggs, 1976; Roth and Hudson, 1985). One distinct teature of the lower liybrid wave is that it can accelerate both elcctrons and ions and might be the source tor auroral precipitating electrons and ion conics (Bingham et al.. 1984: Chang and Coppi, 1981 ).

The whistler and lower hybrid waves excited near the resonance cone are quasi-clectrostatic waves with negligible magnetic components. However, the "funnel-shaped" auroral hiss observed by DE- 1 signifies that the auroral hiss has considerable magnetic components (Cumett et al.. 1983). Subsequent stability analyses using the observed particle distributions have revealed that the electron acoustic wave. 


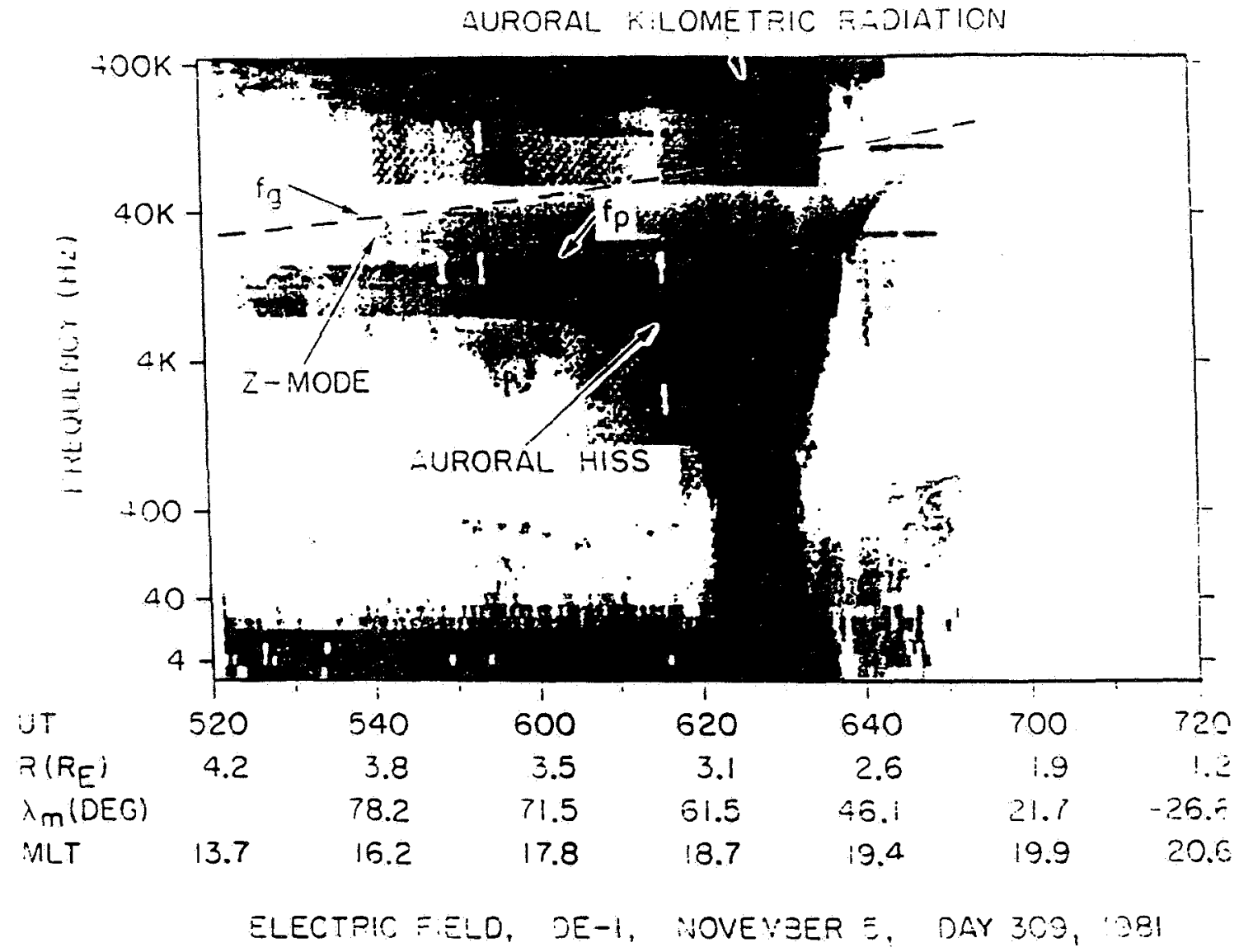

1.ig. 1. A representative spectrogram of the electric tield intensities for a nightside crossing of the auroral tield lines. lhe piasma density over the polar region is relatively low. with $t_{2} \ll t_{\text {. }}$ (irom Gurnett et al.. 1983).

rather than the whistler wave, is the more unstable mode Jriven by the electron beam (Lin et al., 1984, 1985; Tokar and Giary. 1984). The electron acoustic wave is electrostatic in nature and thus might account for the electrostatic compenent of auroral hiss. The ongin of the electromagnetic component of the hiss. however, still remains unanswered. In a ditferent context. Benson et al. (1988) have reported the ground-hased detection of waves in the frequency range of $150-300 \mathrm{kHz}$. which indicates the generation of field-aligned waves $i n$ the auroral zone. The field-aligned waves observed by Benson et al. are electromagnetic and fall into the trequency range of the whistler mode. Motivated by these unservauons. Wu et al. (1989) showed that an energetic clectron population with a temperature anisotropy or a Irapped lype distribution is capable of generating lield-idigned waves in the observed frequency range.

In this paper, we present data obtained from the Plasma Wave Instrument (PWI) and the High Altitude Plasma filstrument (HAPI) onboard the DE-I spacecratt. We are
Inainly interested in electromagnetic waves with trequencies hetween the ion cyclotron and the electron cyclotron frequencies and the correlation of these waves with the plasmas. $\Lambda$ s shown below. we have identified broadband. low-frequency electromagnetic waves in the vicinity of the lower hybrid frequency. We have also found examples of telectromagnetic waves in the whistict trcouency range, which is quite different trom the funnel-shaped auroral hiss. We betieve that these electromagnctic waves are tirst generated either by electron beams or ion rings as the lower hybrid or whistler mode near the resonance cone and acquire electromagnetic components when they propagate away from the sources.

\section{OBSERVATIONS}

Figure 1 shows a frequency-ume spectrogram (from Fig. tof (jurnett et al.. 1983) during a nightside crossing of the auroral ficld lines under the condition that the electron 
plasma trequency, $\omega_{r e}$, is less than the electron cyctotron trequency. 12. The corresponding electric tield intensity spectrum is shown in Figure 2 (from Fig. 5 of Gurnett et al., 1983). These tigures display some common teatures of highirequency clectromagnetuc waves trequenuly observed in the low-density auroral region. At or above the electron cyclotron irequency is the auroral kilometric radiation, which is believed to be in the fast extraordinary $(R-X)$ mode. The $Z$ mode radiacion is observed at or below the tocal electron iyclotron trequency, with some possible overiap of ordinary (L-O) mode radiation (the upper cutoff of the $\mathrm{Z}$ mode is at the upper hybrid frequency, which is very close to the electron cyclotron trequency for a low-density plasma). The auroral hiss is the most commonly observed and is bounded by the elecuron plasma trequency (for $\omega_{r e}<\Omega$.). Auroral hiss (alls into the whister mode range and exhibits a tunnelvhape centered on a region of intense electron precipitation (Ciumett et at., 1983).

Besides the high-frequency electromagneuc waves, lowfrequency electromagneuc waves with frequencies at or below the ion cyclotron frequencies have also been observed in the polar region [see Gurnett et al. (1984) for a detailed discussioni. However. not much attention has been paid to electromagnetic waves between the ion cyclotron and the lower hubrid frequencies. One of the main purposes of the present work is to show that electromagnetic waves in this frequency range are a common occurrence in the polar magnetospnere and to explore the roles that these waves can play in parucle acceleration processes at low altitude. As a tirst eximpie. Plate 1 (adapted from Sharber et al. 1988) hows thic pirucle and wave observations in the dayside curoral tune. The upper panel shows the electron data. The muddle und lower paneis display the electric and magnetic spectra. It is clear from the electric and magnetic field signatures that the most intense electromagnetic waves wcurred between 06:50 UT and 07:15 UT. These clectromagnetuc waves have frequencies between $200 \mathrm{~Hz}$ and 700 IL.. whereas the local electron cyciotron frequency (represented by the dotted line) is approximately $25 \mathrm{kHz}$ and the curresponding hydrogen cyclotron trequency is approximately $13.5 \mathrm{~Hz}$. Thus. these electromagnetic waves are above the ion cyclotron trequency and are in the vicinity of the lower hybrid frequency. Two features of these waves ure worth mentioning. First. these waves occurred outside the regun of intense electron precipitation ( - from 07:45 UT (1) (0):(0) UT in which broadband electrostatic waves are ubserved. Second. the electromagnetic waves are observed at the higher magnetic field side of the electron precipitation. These kitures provide some clue of how these waves are genterated. which we will discuss later.

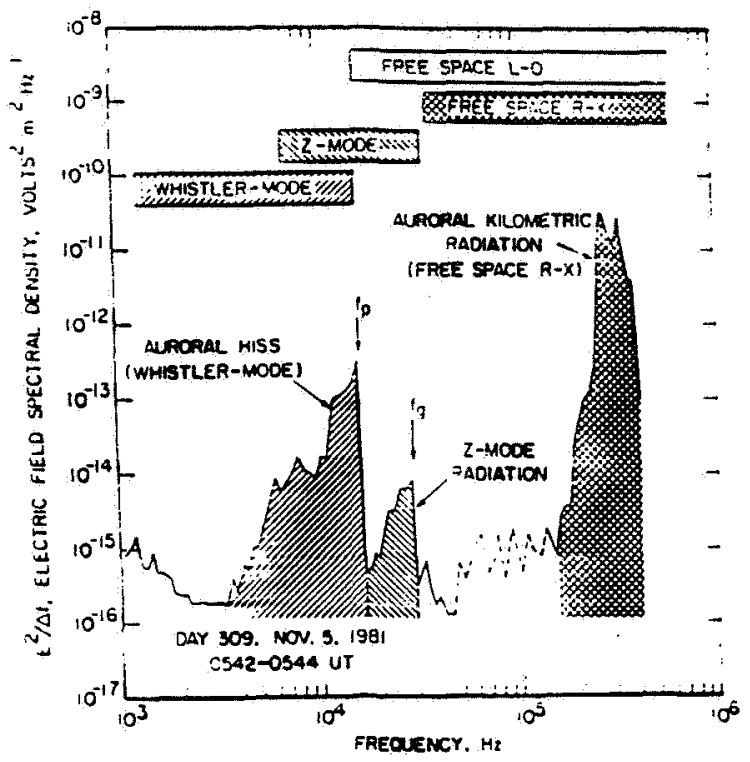

Fig. 2. An electric field intensity spectrum selected from the pass in Figure $\mathbf{l}$ showing the relative intensities of the auroral kilometric radiation. the $\mathrm{Z}$ mode radiation, and the auroral hiss. The sharp upper cutoff of the auroral hiss at $t_{p}$ and the cutoff of the $Z$ mode radiation at $\mathfrak{i}_{3}$ are clearly evident. The dashed line indicates a region where the spectrum is being modified by receiver distortion eifects caused by the very intense kilometric radiation (from Gurnett et al.. 1983).

Plate 2 shows an exampie of particle and wave observations in the nightside auroral zone. The upper panel shows the electron data while the muddle and lower paneis Jisplay the electric and magnetuc ticld data. The electric ticld Jata showed a rather weak auroral kilomeuric radiation. which lies above the electron cyclotron irequency (the upper Jotted line), suggesting that the AKR is generated below the satellite. The funnel-shaped auroral hiss emission shows a strong correlation with the auroral precipitating electrons. which is centered at approximately 07:33 UT. There are two distinct bands of emissions just outside the precipitating region. started from 07:43 UT. The first band of emission has a irequency range from $200 \mathrm{~Hz}$ to $500 \mathrm{~Hz}$. This band of emission is essentually the same type of emission that we just discussed. with frequencies extending from above the ion cyclotron trequency (the lower dotted line) to the lower hybrid frequency. The second band of emission has a trequency range from $500 \mathrm{~Hz}$ to $2 \mathrm{kHz}$. This band of emission has a trequency above the lower hybrid frequency and falls into the whisuler mode range. An examination of the magnetic ficld data suggested that these two bands of emissions are electromagneuc. These two bands of clectromagnetic emissions also have the same features as the case that we discussed above. i.e. they are observed outside 
the region and at the higher magnetuc tield side of intense electron precipitation.

In addition to the two examples shown above. our preiminary survey of the DE plasma wave data has found numerous examples of these electromagneuc waves in the auroral zone. polar cusp, and polar cap. The lower band of these clectromagnetic waves typically has frequencies hetween $100 \mathrm{~Hz}$ and $1 \mathrm{kHz}$, falling between the ion cyclouron and lower hybrid frequencies. The upper band imissions have frequencies above the lower hybrid trequency and are in the whistler mode range. However. their characteristics are very different from the aurorat hiss whistler mode. In the following, we try to identity these siaves and explore the possibilities of how these waves are Ltencrated.

\section{DISCUSSION AND SUMMARY}

()ur initial interpretation of the electromagnetic waves with frequencies between the ion cyclotron and the lower hybrid frequencies are tast magnetosonic waves since fast magnetosonic waves are the only electromagnetic waves in this frequency range that exhibit such characteristics (to our best knowledge). The other band of electromagnetic emissions with frequencies above the lower hybrid frequency (but far below the electron cyclotron trequency) are probably clectromagnetic whistler waves. One immediate question to ask is whether these waves are locally generated and by what mechanisms. It seems highly unlikely that these waves ure incally generated based on the following considerations. trst. une tast magnetosonic wave has a phase speed at or thuve the Alfven speed. which is very high for a low density Plasma tat least of the order of $0.1 \mathrm{c}$, with $\mathrm{c}$ being the speed (1) light). Thus Landau resonance can not easily be satisfied hetween the waves and the parucies. except tor very inergetic electrons $\left(10^{\circ} \mathrm{s}\right.$ of $\mathrm{keV}$ or higher). Hlowever. clectrons with energies $10 \mathrm{keV}$ or higher are seldom whserved in the dayside polar region. Second. when wave irequencics are far above the ion cyclotron frequency but far helow the electron cyclotron trequency. it is very difficult fir eyclotron resonance to occur. This might be the main reisson that tittle attention has been paid to electromagnetic waves $i n$ this frequency range since there is no obvious lirect means of generating electromagnetic waves in this rewime. Third, when these electromagnetic waves are whserved, there is little accivity among the plasmas.

If one rules out the possibility that these waves are locally generated. one can easily provide an explanation for the occurrence of these waves. We suspect that these waves .re evenerated first as lower hybrid waves near the lower ivhrid resonance cone above the satellite in tield lines under which the particle precipitation occurs and propagates downward. Lower hybrid waves can be excied either by clectron beams in the auroral zone or by ion ring distribution in the polar cusp. As the lower hybrid waves propagate toward higher magnetic field strength. the waves become more clectromagnetic and eventually transit into fast magnetosonic waves. As the waves propagate toward lower magnetuc ficld strength, the waves become more electrostatic and arc absorbed by the background plasmas. The same mechanism can also apply to the electromagnetic whistler waves except whistler waves can only be generated by electron beams since the frequency of the waves is too high ior ions to respond. This scenario explains naturally why these waves are mainly observed outside the region and at the higher magnetic ficld side of intense electron precipication.

We now divert our attention to what role the tast magnetosonic waves can play in particle acceleration processes at low altitude. The acceleration of ionospheric ions and the formation of ion conics have been extensively studied in the past. Despite the tact that electrostatic ion cyclotron and lower hybrid heaung are regarded as the promising ion acceleration mechanisms and these waves have trequently been observed in the polar regions, there is no conclusive evidence that these waves are correlated with ion conics (Kitner and Gomey, 1984). Also. there is considerable doubt whether these processes are operative at low altitudes. probably as low as $400 \mathrm{~km}$. where ion conics have been ohserved (Yau et al.. 1983). The electrostatic ion cyclotron waves are difficult to excite at low altitudes since it requires at very large critical current. The lower hybrid wave has too high a phase velocity to resonate with the cold ionospheric ions. One way to get around this difficulty is to assume that the lower hybrid waves undergo a parametric lecay process. The resulting daughter tower hybrid waves have lower phase velocity and can resonate with the thermal ions (Koskinen. 1985: Retterer et al.. 1986). However. this process requires intense lower hybrid pump waves. but there is no strong ohservational support of intense lower hybrid waves at very low altitudes. $\Lambda$ s was just mentioned. fast magnetosonic waves have a very high phase velocity when the wave frequency is not too close to lower hybrid irequency. Thus. the wave cill propagate a long distance downward practically undamped. until the wave trequency is very close to the locad ion cyclotron trequency in which ion cyclotron damping occurs. (The fast magnetosonic wave consists of both right and left hand components. The left hand component contributes to cyclotron damping). This process leads to the heating or acceleration of ions at low altitudes by fast magnetosonic waves originating at high altitudes and also provides additional support that the tast 

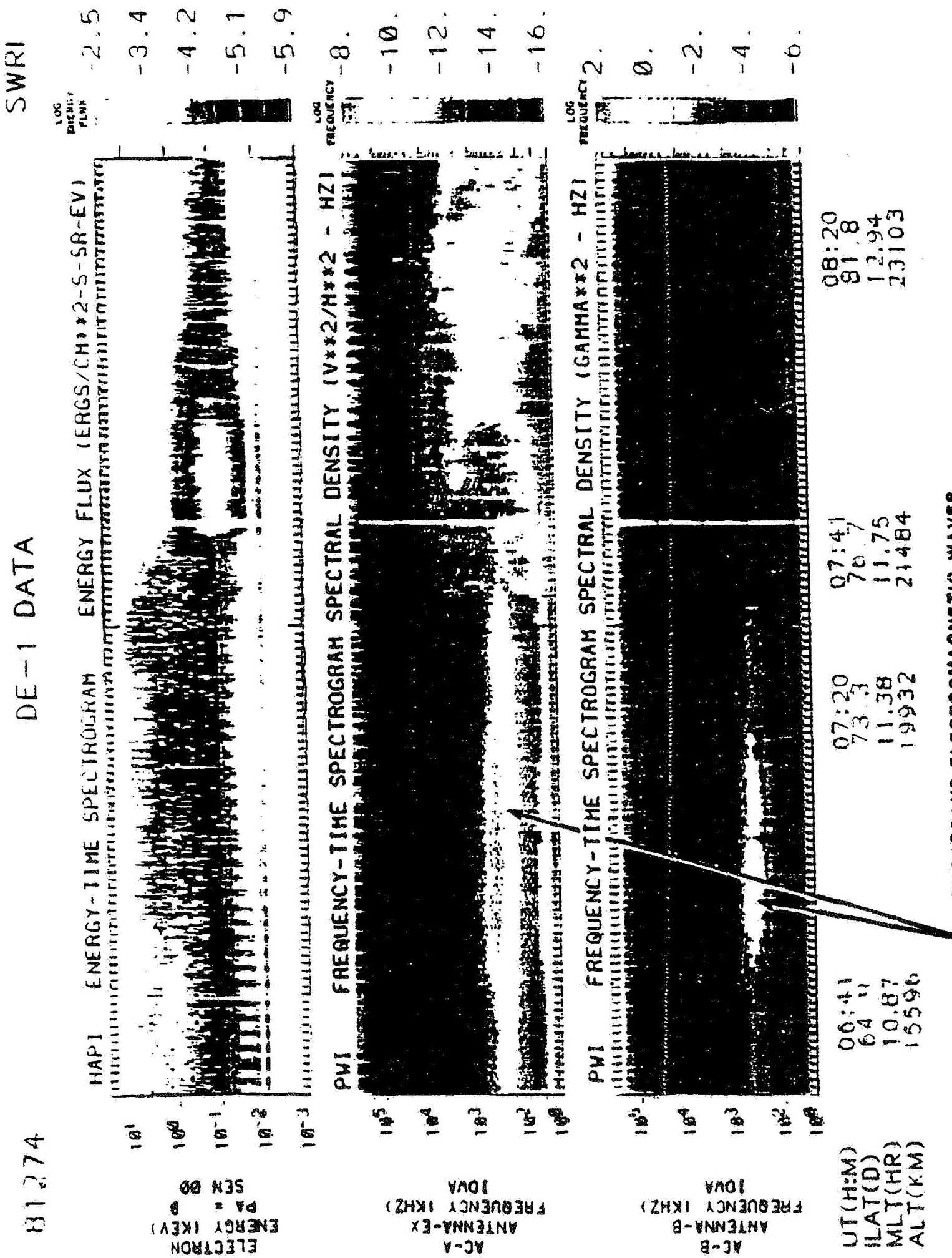

000

舟-
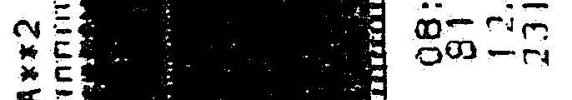

这

远
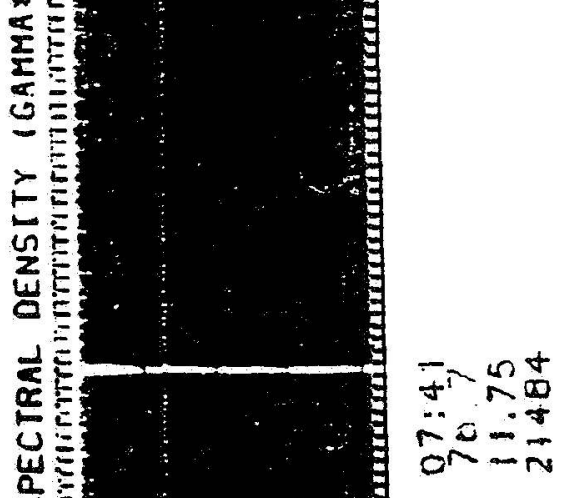

u

ज:

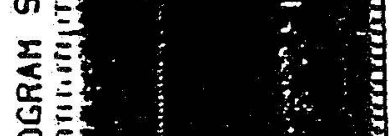

orn

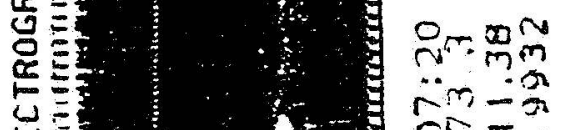

w

올:

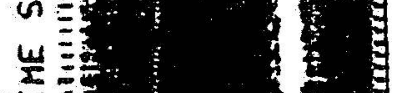

产

产

产产

글

吾

范

巨苔

ב.

窵

氙

竎

曹

吾

产

要

美

产章
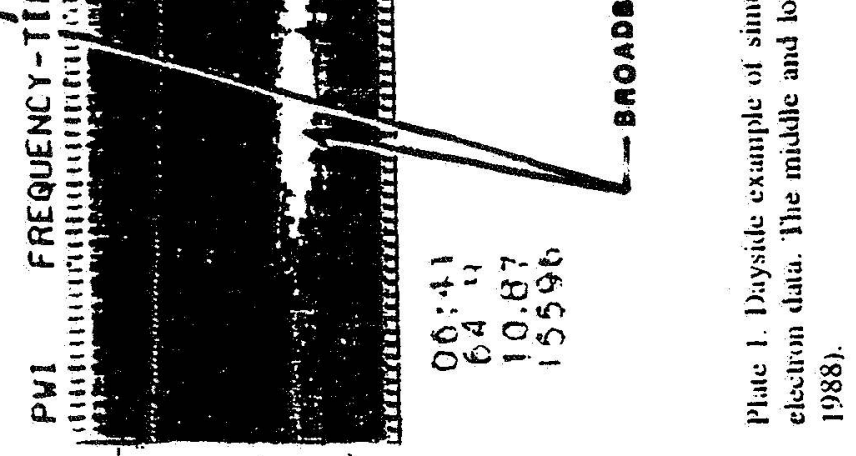

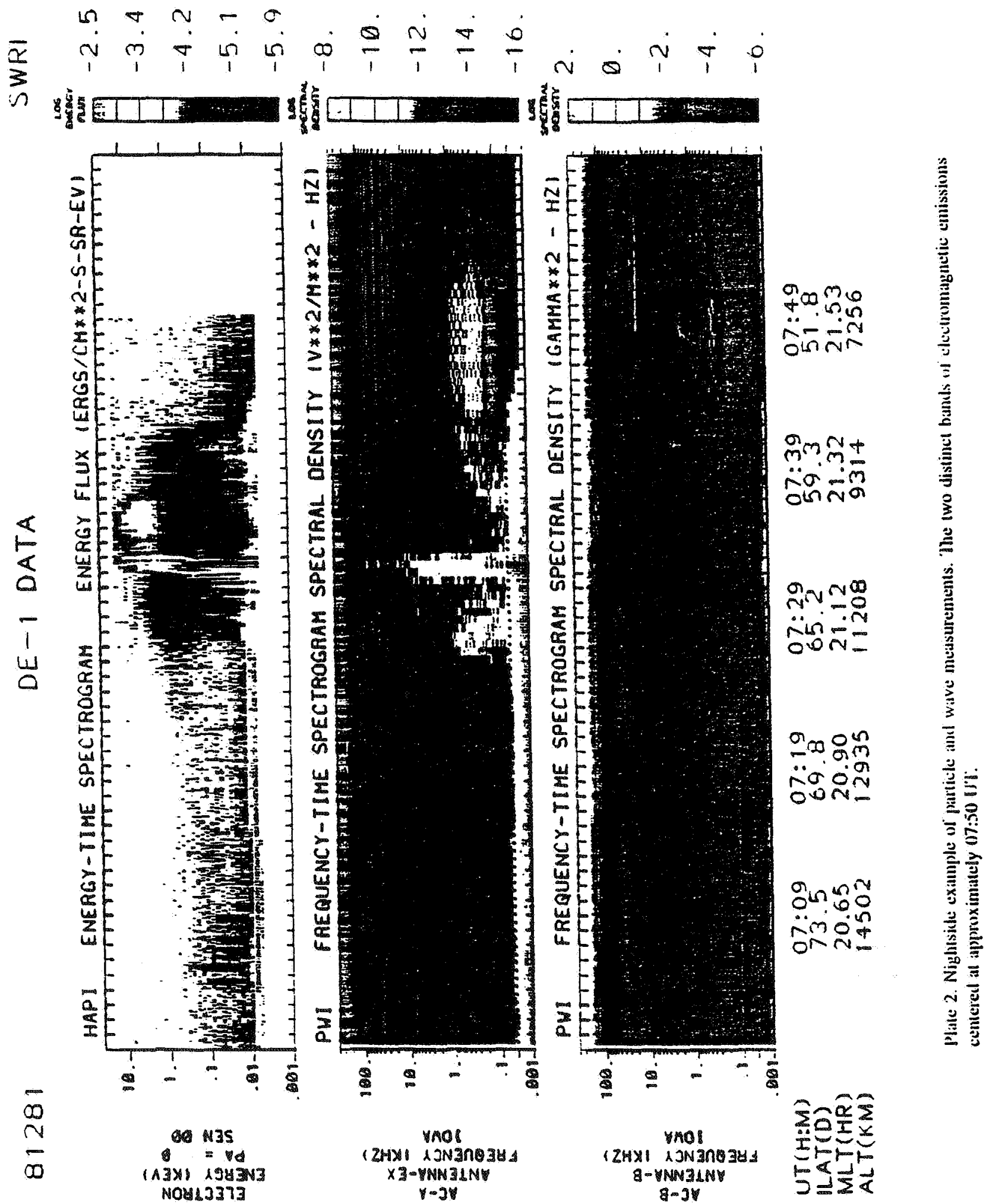

NOUL 3373 
magnetosonic waves are otten observed at above. not below. the ion cyclotron trequency.

In summary. it has been shown through examples trom 1) E: 1 wave and plasma data that electromagnetic waves with trequencies between the ion eyclotron and the electron cyclotron trequenctes are common occurrences in the Earth's polar matonctosphere. It is suggested that these clectromagneuc waves are tirst generated cither by clectron heams or ton rings as the lower hybrid or whistler mode nears the resonance cone and then they acquire electromanetic components when propagated away trom the sources loward higher magnetic field strenguls. The fast magnetosouc waves might play an important role in the acceleration of ions at low altutudes as they propagatc toward the ionosphere. Further studies which include stability analysis using the observed particle distributions. ray tracing. and quasilinear and noniinear analysis are desirable to examme yuanulatively the origin of these waves. how they propagate down to the ionosphere. and their subsequent heatulg of cold ionosphere ions through cyclotron damping.

Acknowledgements. The author would like to thank Doug Meniell and Chin Lin for valuable discussions. This work was supported by NASA grants NAGW-1620 and NAG5-1552.

\section{REFERENCES}

Ashour-Abdalla. M.. and C. F. Kennel. Diffuse aurorai precipitation. J. Geomag. Geoelectr.. 30. 239, 1978.

Benson. R. F.. M. D. Desch. R. D. Hunsucker. and J. G. Romick. (iround-level detection of low and medium-frequency auroral emissions. J. (jeophys. Res.. 93. 277. 1988.

Bingham. R.. D. A. Bryant. and D. S. Hall. A wave model for the aurora. Geophys. Res. Lett. II. 327. 1984.

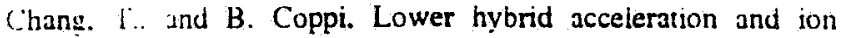
evolution in the suprauroral regions. Geophys. Res. Lett.. 8. 1253. 1981.

Chang. I.. (j. B. Crew. N. Hershkowitz. J. R. Jasperse. J. M. Retterer. and J. D. Winningham. Transverse acceleration of oxygen tons by electromagnetic ion cyclotron resonance with broadband left-hand polarized waves. Geophys. Res. Lett., 13. 636. 1986.

Crew. (i. B.. T. Chang, J. M. Retterer. W. K. Peterson. D. A. (iurnett. and R. L. Huff. Ion cyclotron resonance heated conics: Theory and observations. J. Geophys. Res.. 95. 3959. 1990.

Gurnett. 1). A.. The Earth as a radio source: Terresurial kilometric radiation. J. (ieophys. Res., 79. 4227. 1974.

Girnett. D. A. S. D. Shawhan. and R. R. Shaw. Auroral hiss. Z. mode radiation. and auroral kilometric radiation in the polar magnetospnere: DE-1 observations. J. Geophvs. Res.. 88. 329. 1983.

Gurnetl. 1) A.. R. L. Huff. J. D. Menietti. J. L. Burch. J. D. Winningnam. and S. D. Shawhan. Correlated low-trequency electric and magnetic noise along the auroral lield lines. $J$. (ieophys. Res.. 89.8971. 1984.

Kitner. P. M. and D. J. Ciorney. A search for the plasma processes associated whin perpendicular ion heatung. J. Geophys. Res. 8\%. 937. 1984

Koskinen. H. E. J.. Lower hybrid parametric processes on auroral field lines in the topside ionosphere. J. (ieophys. Re's. 9(). 8361.1985.

Lin.. C. S.. J. L. Burch. S. D. Shawhan. and D. A. (iumett. Correlation of auroral hiss and upward electron beams near the polar cusp. J. Geophvs. Res.. 89. 925. 1984.

Lin. C. S.. D. Winske. and R. L. Tukar. Simulation of the etectron acoustic instability in the polar cusp. J. Geophys. Res.. 90. 8269. 1985.

Lysak. R. L.. Ion acceleration by wave-particle interaction. in lon Acceleration in the Magnetosphere and lonosphere. edited by T. Chang. p. 261. A. G. U.. Washington. D. C.. 1986.

Maggs. J. I:.. Coherent generation of VLF hiss. J. Geophvs. Res. 81. 1707. 1976.

Retterer. J. M.. T. Chang. and J. R. Jasperse. Ion acceleration by lower hybrid waves in the suprauroral region. J. (jeophws. Res.. 91. 1609. 1986.

Roth. I.. and M. K. Hudson. Lower hybrid heating of ionospheric ions due to ion ring distribution in the cusp. J. Geophys. Res.. 90. 4191.1985.

Sharber. J. R.. J. D. Menietti. H. K. Wong. J. L. Burch. D. A. Gurnett. J. D. Winningham. and P. J. Tanskanen. Plasma waves associated with diffuse auroral electrons at mid-altitudes. $A d$. Space Res. 8. no. 9. 447. 1988.

Shawhan. S. D.. Magnetospheric plasma waves. in Solar System Plasma Physics. vol. III. edited by L. J. Lanzerotti. C. F. Kennel. and E. N. Parker. North-Holland. Amsterdam. 1979.

Temerin. M. A.. and D. Cravens. Production of electron conics by stochastic acceleration parallel to the magnetic tielu. J. Geophys. Res.. 9S. 4285. 1990.

Tokar. R. L.. and S. P. Gary. Electrostatic hiss and the heam driven electron acoustic instability in the dayside polar cusp. (ieophys. Res. Letl.. 11. 1180.1984.

Wong. H. K.. J. D. Menietti. C. S. Lin. and J. L. Burch. (jeneration of electron conical distributions by upper hybrid waves in the Earth's polar region. J. Geophys. Res.. 93. 10025. 1988.

Wu. C. S.. and L. C. Lee. $\Lambda$ theory of the terrestrial kilumetric radiation. Astrophys. J.. 230. 621. 1979.

Wu, C. S.. P. H. Yoon. and H. P. Freund. A theory of electron cyclotron waves generated along auroral field lines observed by ground tacilities. Geophys. Res. Lett.. 16. 1461. 1989.

Yau. A. W.. B. A. Whalen. A. G. McNamara. P. J. Kellogg. and W. Bernstein. Particle and wave observations of low altitude ionospheric ton acceleration events. J. Geophys. Res.. 88. 341. 1983.

H. K. Wong. Department of Space Science. Southwest Research Institute. PO Drawer 28510. San Antonio. TX 78228-0510 


\section{Reply}

\author{
Hung $\mathrm{K}$. Wong \\ Aurora Science Incorporated, San Antonio, Texas
}

Charles W. Smith

Bartol Research Institute, University of Delaware, Newark

Orlowski and Russell [this issue] claim that the energetic electron distributions used by Wong and Smith [1994] in a general theoretical study of instabilities at whistler mode frequencies is irrelevant to the wave observations studied by Orlowski and colleagues. We never claimed to model specific electron distributions or to account for particular magnetic wave observations. We begin this reply by clarifying the Orlowski and Russell [this issue] description of our work, and we end it by showing that ample justification can be found in the work of Orlowski a.:d colleagues and elsewhere to justify the pursuit of a better theoretical understanding of these instability mechanisms.

Wong and Smith [1994] focuses primarily on the excitation at $1 \mathrm{AU}$ of parallel-propagating waves at whistler mode frequencies with plasma-frame frequencies in the range 10 to $20 \mathrm{~Hz}$. The spacecraft-frame frequencies tend to be similarly valued, so our paper addresses primarily waves that are observable in the lowest channels of plasma wave experiments. Orlowski and Russell [1991] and Orlowski et al. [1990, 1993, 1995] investigate waves at spacecraft-frame frequencies of $\sim 1 \mathrm{~Hz}$ observed by magnetometers upstream of Mercury, Venus, and Earth.

The principal motivation for our paper is our own work with whistler mode waves upstream of the Uranian bow shock [Smith et al., 1991]. In that study we report two instances of simultaneous whistler mode waves existing at two different spacecraft frequencies, with different propagation directions and different amplitudes. We conclude that the likely source of the observations is a hot electron beam with $T_{\perp b}>T_{\| b}$ originating at or behind the shock. Wong and Smith [1994] carries this analysis to $1 \mathrm{AU}$ and searches for the implications this work might have for whistler mode waves in the terrestrial foreshock.

Energetic electron observations recorded close to the shock [Feldman et al., 1983; Fitzenreiter et al., 1984, 1990; Scudder et al., 1986] justify our range of particle distribution parameters. For instance, Figure 1 of Fitzenreiter et al. [1990] clearly shows several examples of hot electron beams with $T_{\perp b}>T_{\| b}$ and $v_{b}=(4-8) \times 10^{8} \mathrm{~cm} / \mathrm{s}$.

Copyright 1995 by the American Geophysical Union.

Paper number 95JA01126.

0148-0227/95/95JA-01126\$02.00
We take as our base parameterization: $n_{p}=n_{e}=$ $6 \mathrm{~cm}^{-3}, T_{p}=T_{e}=10 \mathrm{eV}, B=5 \mathrm{nT}, n_{b}=0.6 \mathrm{~cm}^{-3}$, $T_{b}=100 \mathrm{eV}, T_{\| b}=T_{\perp b}, v_{b}=3.4 \times 10^{8} \mathrm{~cm} / \mathrm{s}$. "The resulting instability is maximum at parallel propagation with $k=1.6 \times 10^{-6}$ and $\omega=130 \mathrm{rad} / \mathrm{s}(21 \mathrm{~Hz})$. This yields spacecraft-frame frequencies greater than 11 $\mathrm{Hz}$ (if the solar wind speed is $400 \mathrm{~km} / \mathrm{s}$ and the wave propagates sunward along a radial magnetic field) and frequencies as high as $21 \mathrm{~Hz}$ if the wave propagates at right angles to the solar wind velocity. These frequencies are well above the range of any magnetometers used by Orlowski and collaborators.

From this starting point, we vary the above parameters and make use of an anisotropic electron beam. This destabilizes the obliquely propagating waves through the same mechanism as Sentman et al. [1983] and shows that the generation of two simultaneous whistler mode waves at distinct frequencies and propagation directions is again possible at $1 \mathrm{AU}$ as it is at $20 \mathrm{AU}$. We also demonstrate that the beam-plasma system possesses an unstable mode that is left-hand polarized at whistler mode frequencies. We examine the full range of oblique propagation using numerical codes and develop a simple analytical treatment of the parallel-propagating instabilities.

It is possible to produce parallel-propagating waves with Doppler-shifted spacecraft-frame frequencies as low as $1 \mathrm{~Hz}$ if the beam speed is small. We show one such solution in Figure 4 of our paper. However, it is more likely that $1-\mathrm{Hz}$ waves are obliquely propagating when generated by this mechanism and Figures $1,3,4$, and 6 of our paper demonstrate this fact. All of the oblique solutions with large growth rates shown in these figures have spacecraft-frame frequencies of the order of 1 Hz. While Orlowski et al. [1995] contend that a seventemperature distribution of energetic electrons is essen? tial to the interpretation of the oblique whistler mode instability, it is at best desirable for the interpretation of specific events. Our paper is a more general theoretical treatment of the basic instability.

Wong and Smith [1994] does not attempt to link the theoretical treatment discussed above to any specific magnetic wave observations. It is strictly a theoretical discussion of instabilities leading to electromagnetic waves at whistler mode frequencies that may be present in the Earth's foreshock. However, we note that Orlowski and Russell [1991] and Orlowski et al. $[1990,1995]$ claim that $1-\mathrm{Hz}$ magnetic waves originate 
near the shock and propagate into the upstream region. They also acknowledge that the electron distributions observed concurrent with $1-\mathrm{Hz}$ waves in the upstream region may result from the interaction of the beam with preexisting waves and may not represent the source of the $1-\mathrm{Hz}$ fluctuations. The instabilities we discuss could be operating closer to the shock and may be a source of the $1-\mathrm{Hz}$ waves seen further upstream.

Orlowski et al. [1990] report that the majority of 1 $\mathrm{Hz}$ waves upstream of Mercury and Venus are left-hand polarized. Since only Newman et al. [1988] and Wong and Smith [1994] demonstrate the ability to produce left-hand polarized waves at whistler mode frequencies, the possibility that this mechanism may explain the lefthanded waves is worthy of further examination. The relevance of this instability should not be minimized. Orlowoski et al. $[1990 ;$ p. 2295] write about $1-\mathrm{Hz}$ waves üpstreàm of Venus:

upstream of Venus.

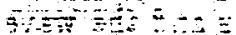

The only waves with sufficient group velocity to stand in the flow are whistler mode waves. ... the observed waves must be in fact right-handed in the plasma frame... This explains the apparent paradox of a lefthanded wave having a compressional component.

The electron population responsible for the whistler waves upstream of Saturn [Orlowski et al., 1992] is not resolved by observations. The implication by Orlowski and Rüssell that further discussion of possible source mechanisms for these waves is irrelevant seems premature.

In summary, Wong and Smith [1994] is a theoretical discussion of electron beam instabilities at $1 \mathrm{AU}$ that emphasized anisotropic temperature distributions in the generation of right- and left-hand polarized electromagnetic waves at whistler mode frequencies. That paper lays the groundwork for an improved theoretical description of these instabilities and provides an analytical treatment of the instabilities. Waves at whistler mode frequencies upstream of planetary bow shocks possess a wide variety of possible sources. We have no quarrel with arguments by Orlowski and coauthors that whistler mode waves in planetary foreshocks may originate close to the shock and may not be excited by the more distant upstream energetic electron distributions observed concurrent with the waves. In fact, we contend that the broad class of energetic electron observations observed close to the shock may provide the source for at least a class of upstream whistler waves. We believe that pursuit of these instabilities over a wide range of parameter space is worthwhile.

Acknowledgments. This work is supported by NASA grant NAGW-3445 and Jet Propulsion Laboratory contract 959167 to the Bartol Research Institute as well as NASA grant NAGW-1620 to the Southwest Research Institute.

\section{References}

Feldman, W. C., R. C. Anderson, S. J. Bame, S. P. Gary, J. T. Gosling, D. J. McComas, M. F. Thomson, G. Paschmann, and M. M. Hoppe, Electron velocity distributions near the Earth's bow shock, J. Geophys. Res., 88, 96-110, 1983.

Fitzenreiter, R. J., A. J. Klimas, and J. D. Scudder, Detection of bump-on-tail reduced electron velocity distributions at the electron foreshock boundary, Geophys. Res. Lett., 11, 496-499, 1984.

Fitzenreiter, R. J., J. D. Scudder, and A. J. Klimas, Threedimensional analytical model for the spatial variation of the foreshock electron distribution function: Systematics and comparisons with ISEE observations, $J$. Geophys. Res., 95, 4155-4173, 1990.

Newman, D. L., R. M. Winglee, and M. V. Goldman, Theory and simulation of electromagnetic beam modes and whistlers, Phys. Fluids, 31, 1515-1531, 1988.

Orlowski, D. S., and C. T. Russell, ULF waves upstream of the Venus bow shock: Properties of the one-Hertz waves, J. Geophys. Res., 96, 11,271-11,282, 1991.

Orlowski, D. S., and C. T. Russell, Comments on the "Electron beam excitation of upstream waves in the whistler mode frequency range" by H. K. Wong and C. W. Smith, J. Geophys. Res., this issue.

Orlowski, D. S., G. K. Crawford, and C. T. Russell, Upstream waves at Mercury, Venus, and Earth: Comparison of the properties of one Hertz waves, Geophys. Res. Lett., 17, 2293-2296, 1990.

Orlowski, D. S., C. T. Russell, and R. P. Lepping, Wave phenomena in the upstream region of Saturn, J. Geophys. Res., 97, 19,187-19,199, 1992.

Orlowski, D. S., C. T. Russell, D. Krauss-Varban, and N. Omidi, On the source of upstream whistlers in the Venus foreshock, Plasma Environments of Non-Magnetic Planets, edited by T. I. Gombosi, pp. 217-227, Pergamon, New York, 1993.

Orlowski, D. S., C. T. Russell, D. Krauss-Varban, N. Omidi, and M. F. Thomsen, Damping and spectral formation of broadband upstream whistlers; J. Geophys. Res., in press, 1995.

Scudder, J. D., A. Mangeney, C. Lacombe, C. C. Harvey, T. L. Aggson, R. R. Anderson, J. T. Gosling, G. Paschmann, and C. T. Russell, The resolved layer of a collisionless, high- $\beta$, supercritical, quasi-perpendicular shock wave, 1, Rankine-Hugonoit geometry, currents, and stationarity, J. Geophys. Res., 91, 11,019-11,052, 1986.

Sentman, D. D., M. F. Thomson, S. P. Gary, W. C. Feldman, and M. M. Hoppe, The oblique whistler instability in the Earth's foreshock, J. Geophys. Res., 88, 2048-2056, 1983.

Smith, C. W., H. K. Wong, and M. L. Goldstein, Whistler waves associated with the Uranian bow shock: Outbound observations, J. Geophys, Res., 96, 15,841-15,852, 1991.

Wong, H. K., and C. W. Smith, Electron beam excitation of upstream waves in the whistler mode frequency range, J. Geophys. Res., 99, 13,373-13,387, 1994.

C.W. Smith, Bartol Research Institute, University of Delaware, Newark, DE 19716. (e-mail: chuck@bartol.udel.edu)

H.K. Wong, Aurora Science Inc., 4502 Centerview Dr., Suite 215, San Antonio, TX 78228. (e-mail: swri::kit)

(Received December 19, 1994; revised February 28, 1995; accepted April 3, 1995.) 